Mar Boix-Sales ${ }^{1}$

Adrián García-Montero²

Jordi Guinot-Bachero ${ }^{3, *}$

1. Enfermera Interna Residente. Unidad Docente Multiprofesional de Atención Familiar y Comunitaria de Castellón. Castellón de la Plana. España.

2. Especialista en Enfermería Familiar y Comunitaria. Enfermero asistencial en Servicio Andaluz de Salud. Sevilla. España.

3. Experto Universitario en heridas UC. Enfermero, Centro de Salud Palleter, Castellón de la Plana, España. Miembro del CATIC, Departamento de Castelló. Miembro del Comité Consultivo del GNEAUPP.

*Autor para correspondencia.

Correo elecrtrónico: ratetaxocolatera@gmail.com (Jordi Guinot Bachero).

\section{Herida avulsiva: efectividad de la terapia de presión negativa en una mordedura de perro}

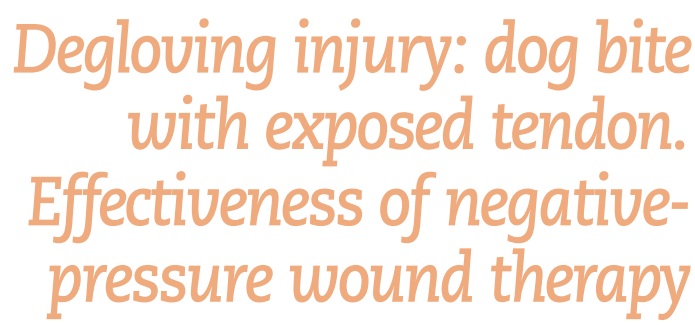

\section{RESUMEN}

Presentamos el caso de una mujer de 84 años que sufrió una mordedura de perro en el brazo, produciéndose, en consecuencia,

una herida avulsiva en el tercio proximal de antebrazo, con la particularidad de dejar el tendón expuesto. En el caso que presentamos proponemos un tratamiento de utilización del colgajo como apósito viable junto al abordaje de la biopelícula, medidas protectoras del tendón y un tratamiento antibiótico. Por otra parte, la aparición de hipergranulación en el lecho de la herida fue un evento adverso que se consiguió resolver favorablemente sin llegar a comprometer la viabilidad del tendón expuesto. La utilización de terapia de presión negativa sobre la lesión logró un avance importante de la epitelización.

En definitiva, la actuación de los profesionales en la consulta de enfermería fue crucial a la hora de facilitar la adhesión al tratamiento, manteniendo así la calidad de vida de la paciente.

PALABRAS CLAVE: Mordeduras, traumatismos de los tendones, manipulaciones musculoesqueléticas, terapia de presión negativa para heridas, lesiones por desenguantamiento, biopelícula bacteriana.

\section{ABSTRACT}

We present the case of an 84-year-old woman who suffered a dog bite on her arm; producing, consequently, an avulsive wound in the proximal third of the forearm, with the peculiarity of leaving the tendon exposed. In the case we present, we propose a treatment for the use of the flap as a viable dressing that, together with the biofilm approach, protects the tendon and an antibiotic treatment. On the other hand, the appearance of hypergranulation in the wound bed was an adverse event that was resolved favorably without compromising the viability of the exposed tendon. The use of Negative Pressure Therapy on the lesion achieved an important advance of the epithelization. In short, the performance of professionals in nursing consultation was crucial in facilitating adherence to treatment, thus maintaining the quality of life of the patient.

KEYWORDS: Bites, tendon injuries, musculoskeletal manipulations, Negative-Pressure Wound Therapy, degloving injuries, bacterial biofilm.

\section{У INTRODUCCIÓN}

Las mordeduras de animales representan un riesgo y un serio problema de salud pública para los humanos.

La Organización Mundial de la Salud ${ }^{1}$ afirma que las mordeduras de perro son de las que más riesgo y gravedad revisten, en función del tamaño del animal, lesiones producidas, estado de salud de la víctima y de la accesibilidad a la red sanitaria.

Los más vulnerables a sufrir una mordedura de perro son los niños y los ancianos. Palacio et al. ${ }^{2}$ afirman que, aunque exista variabilidad en los rangos de edad, actualmente en España los menores de 14 años tienen 4 veces más riesgo de padecer este tipo de mordeduras que el resto de población estudiada. El mayor riesgo de muerte por mordeduras lo sufren los neonatos, los bebés y los ancianos, debido a sus características específicas y a una menor capacidad de defensa ${ }^{3}$.

Para el manejo de estas lesiones, es muy importante controlar el riesgo de infección -ya que entre el $3 \%$ y el $18 \%$ contraen infecciones ${ }^{1}$ - y la posible necrosis de colgajo. Williamson et al. ${ }^{4}$ recomiendan realizar un seguimiento en 24-72 horas para reevaluar la herida y valorar conjuntamente las enfermedades del paciente, la ubicación de la mordida, su complejidad y los riesgos de infección (si es bajo, la OMS ${ }^{1}$ aconseja la práctica de una sutura primaria). Asimismo, si compromete una extremidad y existe riesgo potencial de infección y/o edema ${ }^{5}$, debemos inmovilizarla y elevarla.

Actualmente, una de las opciones recomendadas para acelerar el proceso de cicatrización en las heridas agudas o crónicas es la terapia de presión negativa. En el caso descrito por Saku et al. ${ }^{6}$, este tratamiento resultó ser eficaz a la hora de combatir la infección postoperatoria después de la reparación del tendón de Aquiles de un paciente.

El objetivo principal de este caso es lograr la epitelización total de la lesión. Los objetivos específicos son: controlar la infección y carga bacteriana; evitar los efectos adversos que puedan afectar a la viabilidad del tendón expuesto; conseguir la adhesión al tratamiento y evaluar la relación coste-consecuente del tratamiento. 


\section{HISTORIA CLÍNICA}

Mujer de 84 años, bien nutrida. Demencia senil y Alzheimer diagnosticada en 2017. Sin otras patologías de interés.

\section{Y EXPLORACIÓN}

Herida avulsiva en tercio proximal de antebrazo producida por mordedura de perro, con tendón expuesto. No constan dimensiones ni profundidad en la primera valoración. En la décima cura se registra medición con hoja de evolución RESVECH 2.0 de 14 (fig. 1 A-D) $)^{7-9}$.

\section{Y DIAGNÓSTICO}

La primera visita fue del 24 de agosto de 2018, y únicamente se registró la consulta del médico de atención continuada (tabla 1).

\section{Y PLAN DE ACTUACIÓN}

Se puede observar la evolución de la lesión, conforme a los cuidados, en la tabla 2:

- Manejo de la infección con antibiótico sistémico.

- Eliminación de la biopelícula con desbridamiento seriado cada 3-4 días y apósitos antimicrobianos.

- Adecuación de los apósitos secundarios a las necesidades del exudado.

- Protección del tendón con apósitos de gel o gelificantes para evitar la desecación del paretenón.

- Utilización del dispositivo de un solo uso de terapia de presión negativa (DSUTPN) PICO $7^{\circledR}$ tras descarga bacteriana.

- Prevención y/o resolución de eventos adversos.

- Educación para la salud para fomentar la adhesión al tratamiento.

\section{Y TRATAMIENTO}

Tratamiento inicial: limpieza con suero salino fisiológico + fomento de la herida con solución de polihexanida biguanida (PHMB) (Prontosan solución ${ }^{\circ}$ ) durante 10 minutos + alginato antiadherente con plata (Silvercell ${ }^{\circ}$ ). Entre la $4 \cdot{ }^{a}$ y $8 \cdot{ }^{a}$ cura se añadió malla de hidrocoloides con lípidos $\left(\mathrm{Urgotul}^{\circ}\right)$ como apósito principal.

Abordaje de la biopelícula: limpieza + fomento con PHMB + desbridamiento cortante + hidrogel amorfo sobre tendón + apósitos bactericidas (plata nanoctristalina, Acticoat ${ }^{\circ}$ ) y/o bacteriostáticos como el cloruro de dialquilcarbamilo (DACC, Sorbact ${ }^{\circ}$ ) (fig. 2 A y B), o

Tabla 1. Primera visita médica en Urgencias de Atención Primaria

\begin{tabular}{|l|l|}
\hline Motivo de la consulta & Mordedura de perro conocido \\
\hline Anamnesis & $\begin{array}{l}\text { Al separar sus perros domésticos de una pelea } \\
\text { se ha revuelto uno y le ha mordido en antebrazo } \\
\text { derecho }\end{array}$ \\
\hline Tratamiento & $\begin{array}{l}\text { Derivación al hospital + antibiótico (amoxicilina/ácido } \\
\text { clavulánico } 500 / 125 \mathrm{mg} \text { ) cada } 8 \text { h durante } 10 \text { días }\end{array}$
\end{tabular}
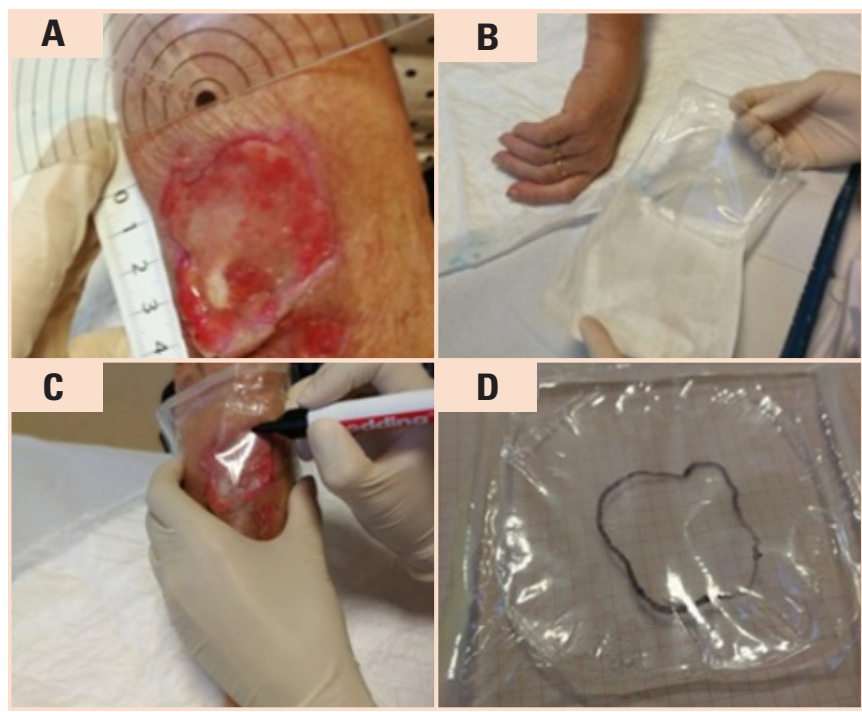

Figura 1. A) Lesión el primer día que abordamos la cura (03/09/2018). Se observa la presencia de tejido de granulación con un exudado abundante de aspecto serohemático, además de una biopelícula madura. Aunque los bordes están relativamente definidos, la parte inferior de la lesión es un colgajo totalmente retraído, el cual rehidratamos mediante un fomento con solución de polihexanida biguanida (PHMB) y reinsertamos definitivamente a la piel con tiras de aproximación durante 24 horas. B). En ausencia de film de poliuretano estéril, utilizamos la cara interna de la cobertura de plástico transparente de un paquete de gasas estériles. C). Con un rotulador indeleble se perfila el perímetro de la herida. D). Este mismo día, se evalúa mediante la escala RESVECH 2.0 la herida obteniendo un resultado de 14. En la imagen se muestra cómo, colocando el plástico sobre el papel milimetrado de electrocardiograma, se mide el área en $\mathrm{cm}^{2}$.
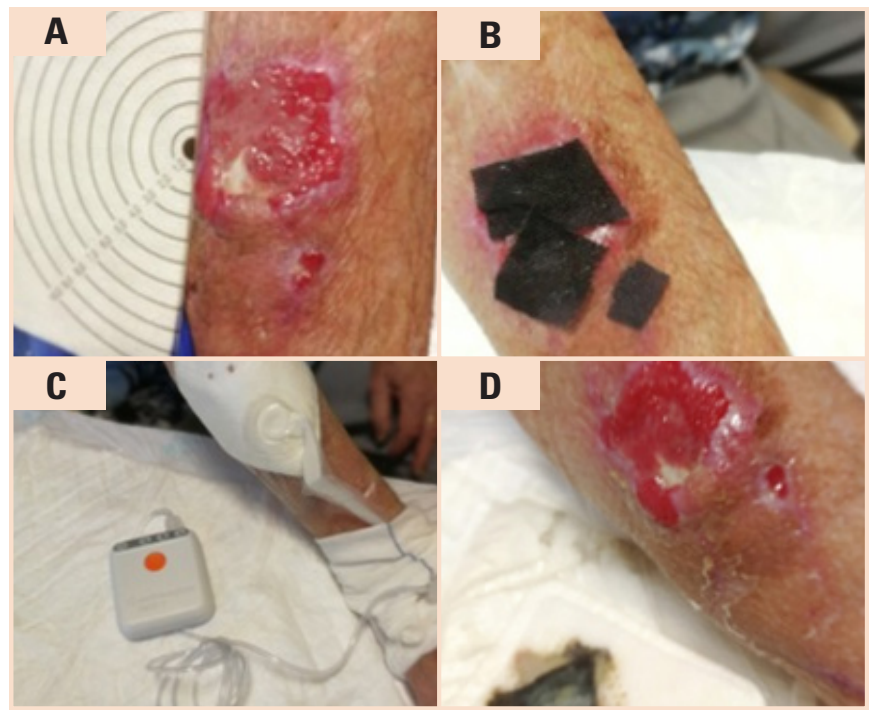

Figura 2. A) Colgajo ya reinsertado a la piel, reduciendo así la zona de tendón expuesto. B) Aplicamos apósito lípido-coloide de tejido de poliéster impregnado con partículas hidrocoloides y vaselina sobre el tendón expuesto y malla de fibra de plata nanocristalina en el resto de la lesión para evitar el crecimiento del biofilm. C). Aplicación del dispositivo de un solo uso de terapia de presión negativa (DSUTPN) para acelerar el crecimiento del tejido de granulación. D) Lesión tras 8 días de aplicación de terapia de presión negativa. Se suspende entonces el uso del DSUTPN por la aparición de tejido hipergranulado en la herida, que no se logró controlar con crema de corticoide. 
Tabla 2. Registro de las consultas de Enfermería durante el proceso de evolución de la herida. Los aspectos de la herida que no están descritos no aparecen en la exploración

\begin{tabular}{|c|c|}
\hline Día/s & Plan de cuidados \\
\hline 25 y $27 / 08 / 18$ & Limpieza con suero fisiológico (SF) + fomentos con solución de polihexanida biguanida (PHMB) + alginato con Ag antiadherente + vendaje de sujeción \\
\hline $\begin{array}{l}\text { Del } 28 / 08 / 18 \\
\text { al } 01 / 09 / 18\end{array}$ & $\begin{array}{l}\text { Limpieza con SF + fomento PHMB + malla de hidrocoloide + alginato con Ag antiadherente + gasa + venda de algodón de relleno + venda } \\
\text { de crepé. Cura diaria }\end{array}$ \\
\hline 03/09/18 & $\begin{array}{l}\text { Limpieza + fomento con PHMB + desbridamiento cortante de la biopelícula + hidrogel + cloruro de dialquilcarbamilo (DACC) + espuma de } \\
\text { poliuretano + vendaje de sujeción }\end{array}$ \\
\hline 04/09/18 & Limpieza con SSF + fomentos con PHMB + hidrogel + DACC + foam. Nueva cura en 24 horas por exudado abundante \\
\hline 05/09/18 & Limpieza + fomento con PHMB + desbridamiento cortante de la biopelícula + hidrogel + DACC + foam + vendaje de sujeción \\
\hline 07/09/18 & Limpieza + fomento con PHMB + PHMB en gel + malla de plata nanocristalina + Apósito de foam \\
\hline 10/09/18 & Fomento con Prontosan + SF + tiras de aproximación para acercar colgajo + malla de plata nanocristalina + alginato + foam de silicona \\
\hline $11 / 09 / 18$ & $\begin{array}{l}\text { Fomentos con PHMB } 15 \text { min + SF + apósito lípido-coloide de tejido de poliéster impregnado con partículas hidrocoloides y vaselina en } \\
\text { tendón expuesto + malla de fibra de plata nanocristalina + DSUTPN + sujeción }\end{array}$ \\
\hline 14/09/18 & $\begin{array}{l}\text { Fomento con Prontosan } 10 \text { min + SF + crema de corticoide en tejido hipergranulado + malla de hidrocoloide en tendón expuesto } \\
(\text { aprox. } 1 \mathrm{~cm})+\text { malla de plata nanocristalina + DSUTPN }\end{array}$ \\
\hline 18 y 19/09/18 & $\begin{array}{l}\text { Limpieza + fomento con PHMB + compuesto liofilizado de colágeno celulosa oxidada regenerada (COR) y plata sobre zona del tendón + } \\
\text { corticoide pomada sobre hipergranulación + malla de nylon y carbón activado con plata + foam + cinta adhesiva } \\
\text { Suspendo DSUTPN por no justificarse coste-eficiente }\end{array}$ \\
\hline $21 / 9 / 18$ & $\begin{array}{l}\text { Limpieza + fomento + betametasona al 0,5 mg/g sobre hipergranulación + hidrogel amorfo sobre tendón + malla de plata } \\
\text { nanocristalina sobre hipergranulación + alginato con carboximetilcelulosa (CMC) + foam }\end{array}$ \\
\hline $\begin{array}{l}\text { Del 25/9/18 } \\
\text { al } 4 / 10 / 18\end{array}$ & $\begin{array}{l}\text { Limpieza con SF + fomento con PHMB + nitrato de plata sobre hipergranulación + malla de plata nanocristalina + alginato con } \\
\mathrm{CMC}+\text { gasa + apósito simple + tiras de presión sobre zona de hipergranulación }\end{array}$ \\
\hline $5 / 10 / 18$ & Limpieza + fomento + foam con plata \\
\hline $10 / 10 / 18$ & Epitelización completada \\
\hline
\end{tabular}

DSUTPN: dispositivo de un solo uso de terapia de presión negativa.

apósito de malla de carbón activado con plata (Actisorb $\left.{ }^{\circ}\right)+$ espuma de poliuretano + vendaje.

Ayuda a la reparación tisular: limpieza + fomento + malla de hidrocoloide con lípidos sobre tendón + apósitos bactericidas + DSUTPN (fig. 2 C y D).

Resolución de la hipergranulación (fig. 3 A y B): se suspende la cura húmeda y se asocian apósitos bacteriostáticos a la crema de corticoide y apósito de gasa.

Ayuda a la regeneración epitelial (fig. $3 \mathrm{C} \mathrm{y} \mathrm{D):} \mathrm{limpieza} \mathrm{+} \mathrm{desbridamien-}$ to cortante de la hiperqueratosis del borde + apósito de espuma con plata.

\section{УEVOLUCIÓN}

La utilización del colgajo como apósito biológico y la aplicación del tratamiento para la eliminación de la biopelícula favorecieron la epitelización total de la herida en menos de 30 días. El evento adverso fue la hipergranulación del lecho, que con la actuación llevada a cabo no llegó a comprometer la viabilidad del tendón.

\section{Y DISCUSIÓN}

El abordaje inicial de las mordeduras es fundamental para lograr una buena evolución. Tal como se describe en la literatura disponible, un

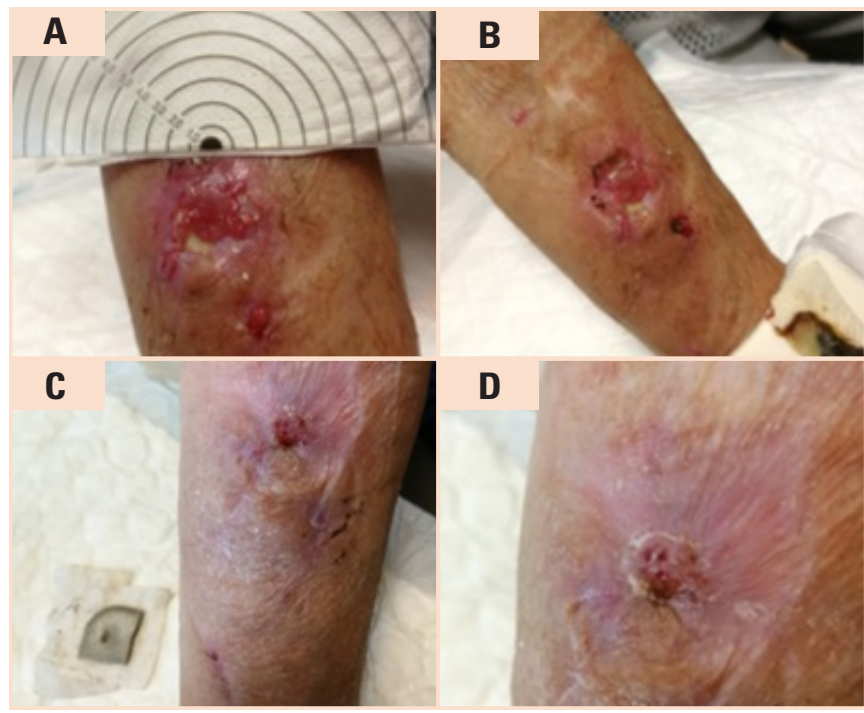

Figura 3. A y B) Evolución de la lesión tras retirar el dispositivo de un solo uso de terapia de presión negativa. La cura a partir de este momento consistió en aplicar sobre el tejido hipergranulado nitrato de plata y tiras de presión. En el resto de la lesión, utilizamos malla de plata nanocristalina y alginato con CMC. C y D) Completa epitelización de la herida. 
tratamiento inicial mediante un lavado intenso con las soluciones bactericidas adecuadas ${ }^{5}$ hubiese permitido una primera cura con sutura y cierre por tercera intención que hubiese protegido el tendón expuesto y facilitado la limpieza del resto del lecho. Una temprana instauración del tratamiento antibiótico por vía sistémica habría evitado el riesgo de infección ${ }^{10}$.

El tratamiento tópico inicial (tabla 2), con mucha probabilidad, retrasó la cicatrización de la herida, pues se omitió el desbridamiento seriado de la biopelícula que recubría el lecho de la herida. La utilización de una malla de hidrocoloides con lípidos como interfase entre el lecho de la herida y el apósito antiadherente de alginato con plata, además de carecer de evidencia, pudo entorpecer el intercambio iónico de la plata con el lecho de la herida y, por lo tanto, aumentar el tamaño y virulencia de la biopelícula ${ }^{11}$.

A partir de la 9. ${ }^{a}$ cura se interrumpió tanto la variabilidad de los profesionales que realizaban la cura como de los tratamientos aplicados. Utilizar diferentes criterios de cura en un espacio de tiempo muy corto tiende a empeorar la evolución, ya que puede producirse una imitación reiterada de la pauta anterior o bien una modificación sistemática de la cura sin criterio de eficiencia ${ }^{12}$. Eliminar la variabilidad y establecer un plan de actuación de enfermería basado en la evidencia ${ }^{13,14}$ nos permitió marcar las mejores pautas clínicas para la resolución del caso.

El desbridamiento cortante de los detritos del lecho de la herida, para eliminar la biopelícula y facilitar la acción de los apósitos bactericidas, ayudó a recuperar el equilibrio bacteriano. Junto al desbridamiento, el empleo de malla de plata nanocristalina impide la reproducción de la biopelícula bacteriana ${ }^{11,15}$. En cuanto a la retracción del colgajo en la zona distal de la herida, se resolvió rehidratándolo con fomento de solución de PHMB durante 10 minutos, lo que dotó al colgajo retraído y enrollado sobre sí mismo de la flexibilidad suficiente como para poder traccionarlo y fijarlo a la epidermis sana con una tira de aproximación ${ }^{16}$. Esta operación permitió cubrir parcialmente el tendón expuesto y facilitó la aplicación del DSUTPN.

En este caso, la utilización en la herida del DSUTPN en formato de PICO $7^{\oplus 17}$, pese a las contraindicaciones incluidas en el prospecto de no aplicar sobre estructuras nobles o heridas infectadas, estuvo precedida por la descarga bacteriana. Cuando se utiliza el DSUTPN en grandes cavidades y se rellena el defecto cutáneo con espuma ${ }^{18,19}$, se protege el lecho de la herida con apósitos de malla de hidrocoloide. Aunque el dispositivo lleva incorporada una malla de silicona que impide la adherencia al lecho de la herida ${ }^{20}$, no encontramos bibliografía de su uso sobre estructuras nobles. Por el contrario, en los dispositivos portátiles de VAC, al utilizar una espuma de alcohol de polivinilo, sí que estaría descrito e indicado ${ }^{19}$. Por eso, y por evitar el riesgo de desecación excesiva del paratenón, optamos por cubrir la zona tendinosa expuesta con una malla de hidrocoloide con lípidos.

Al retirar el DSUTPN, se apreció hipergranulación en los bordes. Como coincidió con el fin de semana, se optó por aplicar una sola dosis de crema de betametasona con una concentración de $0,5 \mathrm{mg} / \mathrm{g}$ para reducir el factor inflamatorio de la hipergranulación, y se cubrió con apósitos bactericidas en combinación con otros de cura en ambiente húmedo. Esto reveló ser una mala decisión, ya que dicha combinación produjo la hipergranulación de todo el lecho. Este efecto adverso se resolvió con la utilización conjunta de crema de betametasona $0,5 \mathrm{mg} / \mathrm{g}$ y apósitos bactericidas de plata y apósitos de alginato ${ }^{21}$. En este segundo tratamiento, como apósito secundario, se evitó la cura en ambiente húmedo y se optó por la fijación con cinta adhesiva quirúrgica o apósitos simples.

La justificación de la utilización de DSUTPN en este caso viene dada por el acortamiento del tratamiento y por una mejora en la calidad de vida de la paciente ${ }^{22}$.

Existe el sesgo de que, en algunos registros, el personal de enfermería no deja constancia de la exploración de la herida. Eso dificulta la valoración de los primeros días de evolución de la lesión. Una futura línea de investigación podría ser la utilización de los DSUTPN como apósito de elección tras el estiramiento y recolocación de un colgajo de una herida avulsiva sobre el lecho de la herida.

\section{$\checkmark$ CONCLUSIONES}

El correcto abordaje inicial de la herida producida por mordedura de perro es crucial para una rápida resolución de la misma.

La variabilidad en los tratamientos aplicados ha entorpecido la correcta evolución del proceso de cicatrización. La utilización del DSUTPN ha sido coste-consecuente al disminuir el número de curas, favorecer la correcta evolución de la estructura noble expuesta y reducirle la ansiedad a la paciente.

El único efecto adverso fue la hipergranulación, que retrasó la cicatrización una semana

\section{Conflicto de intereses}

Los autores declaran no tener ningún conflicto de intereses.

\section{BIBLIOGRAFÍA}

1. Organización Mundial de la Salud (OMS). Mordeduras de animales [Internet]. 2018. Disponible en: https://bit.ly/2UbG5yt

2. Palacio J, León M, García-Belenguer S. Aspectos epidemiológicos de las mordeduras caninas. Gac Sanit [Internet]. 2005;19(1):50-8. Disponible en: https://bit.ly/2pSIB28

3. Barcones Minguela F. Mordeduras y picaduras de animales. Protocolos Diagnóstico-terapéuticos de Urgencias Pediátricas SEUP-AEP [Internet]. 2010;173-87. Disponible en: https://bit. Iy/2S72EHa

4. Andrew Williamson M, Cyril Thomas M. A Clinical Approach to Animal Bites with an Avulsion Flap: A Case Report. Perm J [Internet]. 2017:21:28-9. Disponible en: https://bit.ly/2Ucnpi6

5. Liu-Wu Y-C, Orozco-Cárdenas A. Tratamiento de las mordeduras de perro. Rev Médica Costa Rica y Centro América [Internet]. 2014;(610):289-92. Disponible en: https://bit.ly/2SGKXLE

6. Saku I, Kanda S, Saito T, Fukushima T, Akiyama T. Wound management with negative pressure wound therapy in postoperative infection after open reconstruction of chronic Achilles tendon rupture. Int J Surg Case Rep [Internet].
2017;37:106-8. Disponible en: http://dx.doi.org/10.1016/j. ijscr.2017.06.027

7. Ibars-Moncasi P, San Sebastián-Domínguez JA, Soldevilla-Agreda JJ. Conjunto Mínimo Básico de Datos en registros de Úlceras por Presión (CMBD-UPP). Documento de posicionamiento n. ${ }^{0} 11$. GNEAUPP [Internet]. 2012 p. 5-16. Disponible en: https://bit. ly/2R9Wrpw

8. Restrepo-Medrano JC. Instrumentos de monitorización clínica y medida de la cicatrización en úlceras por presión (UPP) y úlceras de la extremidad inferior (UEI). Desarrollo y validación de un índice de medida. [Internet]. Universitat d'Alacant. 2010. Disponible en: https://bit.ly/2S3rMPc

9. Bilgin M, Günes U. A comparison of 3 wound measurement techniques: effects of pressure ulcer size and shape. J Wound Ostomy Cont Nurs [Internet]. 2013;40(6):590-3. Disponible en: https://bit.ly/2Wdq3pG

10. Nel Carreño J, Dominguez Torres MT. Mordedura humana y por animales. En: Guías para manejo de Urgencias [Internet]. 2009. p. 113-25. Disponible en: https://bit.ly/2Hu6c2m

11. Unión Mundial de Sociedades de Cicatrización de Heridas (World
Union of Wound Healing Societies; WUWHS). Tratamiento de Biofilm. Congr Florencia, Doc Posición [Internet]. 2016;28. Disponible en: www.wuwhs.net

12. Esperón Güimil JA, Loureiro Rodríguez MT, Antón Fuentes VM, Rosendo Fernández JM, Pérez García I, Soldevilla-Agreda JJ. Variabilidad en el abordaje de las heridas crónicas: ¿qué opinan las enfermeras? Gerokomos [Internet]. 2014;25(4):171-7. Disponible en: https://bit.ly/2xF8D97

13. Consenso Internacional. La importancia de un tratamiento eficiente de heridas. Wounds Int [Internet]. 2013;24. Disponible en: https://bit.ly/2HtD4bB

14. Roberta Freitas da Silva G, Moura Carvalho EC, Rodriques Barbosa de Sousa JE, Barradas Cavalcante T, Braz Milanez Oliveira F. Protocolo clínico de heridas: evidencias en úlcera por presión y quemaduras en la práctica de enfermería Evidentia [Internet]. 2012;9(37). Disponible en: https://bit. Iy/2R9G5NC

15. Secinti K, Özalp H, Attar A, Sargon M. Nanoparticle silver ion coatings inhibit biofilm formation on titanium implants. J Clin 
Neurosci. 2011;18(3):391-5. Disponible en: https://www.ncbi. nlm.nih.gov/pubmed/21256031

16. Rumbo Prieto JM, Palomar Llatas F. Lesiones cutáneas laceradas (skin tears), ¿qué sabemos sobre ellas? Enfermería Dermatológica [Internet]. 2015;9(24):7-9. Disponible en: https:// bit.ly/2U79FFi

17. Wound Source. PICO* 7 Single Use Negative Pressure Wound Therapy System [Internet]. 2018. Disponible en: https://bit.ly/2HufgnX
18. Apelqvist J, Willy C, Fagerdahl A-M, Fraccalvieri M, Malmsjö M, Piaggesi $A$, et al. EWMA Document: Negative Pressure Wound Therapy Overview, Challenges and Perspectives. J Wound Care [Internet]. 2017;26(3):1.154. Disponible en: https:// bit.ly/2Dvpcth

19. KCI V... ${ }^{\circledR}$ Therapy Indications and Safety Information [Internet]. 2013. Disponible en: https://bit.ly/2R7pqdC

20. Shim HS, Choi JS, Kim SW. A Role for Postoperative Negative Pressu- re Wound Therapy in Multitissue Hand Injuries. Biomed Res Int [Internet]. 2018;7. Disponible en: https://doi.org/10.1155/2018/3629643

21. Chaverri Fierro D. Hipergranulación en heridas crónicas: Un problema ocasional pero no infrecuente. Gerokomos [Internet] 2007:18(3):150-4. Disponible en: https://bit.ly/2SOZapY

22. González-Consuegra RV Verdú J. Calidad de vida relacionada con heridas crónicas. Gerokomos [Internet]. 2010;21(3):131-9. Disponible en: https://bit.ly/2gM6AJd 